\title{
Predictors of Adverse Outcome following Percutaneous Coronary Intervention
}

\author{
MSR Patwary \\ Department of cardiology, National Institute of Cardiovascular Disease, Dhaka.
}

\begin{abstract}
:
Key words:

Predictors of

coronary

intervention, Coronary artery

disease

Day by day with the experiences and advancement in technology angioplasty has become more refined with higher rate of success and lower rate of complications. In spite of these there remain some of adverse outcomes following procedure. To minimize procedural complications and adversities were looked for evaluation of high risk features. Percutaneous coronary intervention related mortality is directly related to the episode of coronary artery occlusion and is associated with pronounced left ventricular failure. The variables associated with increased mortality include type $C$ lesion, advanced age, female gender, diabetes, ST segment elevated myocardial infraction, prior myocardial infraction, multivessel disease, left main or equivalent coronary disease, a large area of myocardium at risk, preexisting impairment of left ventricular or renal function, post-percutaneous coronary intervention worsening of renal function, and collateral vessels supplying significant areas of myocardium that originate distal to the segment to be dilated.
\end{abstract}

(CVJ 2008; 1(1) : 72-77)

\section{Introduction:}

Coronary angioplasty was first introduced by Andreas Gruentzig in 1977 as a non-surgical method for coronary arterial revascularization. ${ }^{1}$ Now coronary angioplasty could be applied to broad group of coronary artery disease patients with success compared to initial experience. ${ }^{2,3}$ Angiografic success occurs in over $95 \%$ of patients. ${ }^{4}$ Percutaneous coronary intervention now includes other new techniques capable of reliving coronary narrowing including implantation of intracoronary stents, rotational atherectomy, directional atherectomy, extraction atherectomy, laser angioplasty and other catheter devices for treating coronary athersclerosis.

During recent years, numerous clinical and procedural risk factors for adverse outcome after percutaneous coronary intervention have been identified. In the majority of patients undergoing elective percutaneous coronary intervention, death is directly related to the occurrence of coronary artery occlusion and is most frequently associated with pronounced left ventricular failure. ${ }^{5,6}$ The clinical and angiographic variables associated with increased mortality include advanced age, female gender, diabetes, recent myocardial infraction, multivessel disease, cardiogenic shock, emergency percutaneous coronary intervention, peripheral vascular disease, left main or equivalent coronary disease, a large area of myocardium at risk, pre-existing impairment of left ventricular or renal function, post- percutaneous coronary intervention worsening of renal function, AHA/ACC type $\mathrm{C}$ lesion and collateral vessels supplying significant areas of myocardium that originate distal to the segment to be dilated. 5,7,8,9,10,11,12 Peri-procedural stroke also increases in-hospital and 1-year mortality ${ }^{13}$. Percutaneous coronary intervention in the setting of ST segment elevation myocardial infraction is associated with a significantly higher death rate than is seen in elective percutaneous coronary intervention.

As the scope of percutaneous coronary intervention broadens and the complexity of cases increases, there is a pressing need to quantify individual risk to alert both the patient and the cardiologist to the likelihood of an adverse outcome. It also relives undue anxiety for low risk patients and undue reassurance for high risk patients. In this review article we discussed the factors which influence adverse outcome of percutaneous coronary intervention.

\section{Lesion Morphology:}

Diffuse (length greater than $2 \mathrm{~cm}$ ) lesion, excessive tortuosity of proximal segment, extremely angulated (greater than $90^{\circ}$ ) segments, total occlusions more

Address Correspondence : Dr. Mohammad Shafiqur Rahman Patwary, Department of Cardiology ,National Institute of Cardiovascular Disease, Dhaka. Email: dr_md_shafiqur_rahman@ yahoo.com,shafiqur.p@gmail.com 
than 3 months old and/or bridging collaterals, inability to protect major side branches, degenerated vein grafts with friable lesions are high-risk lesion (type $\mathrm{C}$ lesion) for percutaneous coronary intervention .Complex coronary lesions remain predictive of adverse events after percutaneous coronary intervention. The risk of restenosis and technical failure remains high for chronic total occlusions.

More simplified committee of the Society for Cardiac Angiography and Intervention (SCAI) lesion classification provided better discrimination for success and complications. ${ }^{14}$

Type I lesions (highest success expected, lowest risk)

(1) Does not meet criteria for C lesion.

(2) Patent

Tjpe II lesions

(1) Meets any of these criteria for C lesion Diffuse (greater than $2 \mathrm{~cm}$ length) excessive tortuosity of proximal segment extremely angulated segments greater than $90^{\circ}$, inability to protect major side branches degenerated vein grafts with friable lesions.

(2) Patent

Type III lesions

(1) Does not meet criteria for C lesion.

(2) Occluded

Type IV lesions

(1) Meets any of the criteria for C lesion includes diffuse (greater than $2 \mathrm{~cm}$ length), excessive tortuosity of proximal segment, extremely angulated segments greater than $90^{\circ}$, inability to protect major side branches, degenerated vein grafts with friable lesions and occluded for more than 3 months .

(2) Occluded

\section{Clinical and biochemical factors:}

Several studies have reported specific factors associated with increased risk of adverse outcome after percutaneous translumina coronary angioplasty. These factors include advanced age, female gender, unstable angina, congestive heart failure, diabetes, and multivessel coronary artery disease. ${ }^{7,9,10,15}$ Elevated baseline C-reactive protein has recently also been shown to be predictive of 30day death and myocardial infraction. ${ }^{15}$ Other markers of inflammation, such as interleukin- 6 and other cytokines, have also been shown to be predictive of outcome. ${ }^{16}$ The bypass angioplasty revascularization investigation (BARI) trial found that patients with diabetes and multivessel coronary artery disease had an increased peri procedural risk of ischemia and increased 5-year mortality. Patients with impaired renal function, especially those with diabetes, are at increased risk for contrast nephropathy and increased 30-day and 1-year mortality. Renal insufficiency is a strong predictor of outcome in both primary and elective percutaneous coronary intervention. Increased risk for death or severe compromise in LV function may occur in association with a complication involving a vessel that also supplies collateral flow to viable myocardium.

Composite 4-variable scoring system, in predicting cardiovascular collapse for failed percutaneous translumina coronary angioplasty, which includes: 1) percentage of myocardium at risk (e.g., greater than $50 \%$ viable myocardium at risk and left ventricular ejection fraction of less than $25 \%$ ), 2) pre-angioplasty percent diameter stenosis, 3) multivessel coronary artery disease, and 4) diffuse disease in the dilated segment or a high myocardial jeopardy score. Patients with higher pre-procedural jeopardy scores were shown to have a greater likelihood of cardiovascular collapse when abrupt vessel closure occurred during percutaneous translumina coronary angioplasty. ${ }^{5}$

\section{Left main coronary artery disease:}

Coronary artery bypass graft has long been considered the "gold standard" for revascularization of lesions in the unprotected left main coronary artery. ${ }^{17}$ Stenting of the unprotected left main is feasible with unacceptably high incidence of longterm adverse events in the pre- drug eluting stent era. ${ }^{18,19}$ This may be attributed to the inclusion of high risk patients, such as those not considered good surgical candidates.

In general, younger patients with preserved left ventricular function, noncalcified coronary arteries, and complete delivery of stent shows fairly better outcome.

Coronary artery bypass graft using internal mammary artery grafting is the "gold standard" for treatment of unprotected left main disease and has proven benefit on long-term outcomes. The use of drug eluting stent has shown encouraging short 
term outcomes, but long term follow-up is needed. Percutaneous coronary intervention for patients with significant unprotected left main stenosis, can improve cardiovascular outcomes and is a reasonable revascularization strategy in carefully selected patients who are not suitable for coronary artery bypass graft.

\section{Women:}

Early reports of patients undergoing percutaneous translumina coronary angioplasty revealed a lower procedural success rate in women. ${ }^{20}$ In several large scale registries, in-hospital mortality is significantly higher in women. ${ }^{21}$ The higher incidence of vascular complications, coronary dissection, and perforation in women undergoing coronary intervention has been attributed to the smaller vasculature in women than in men. It has also been postulated that the volume shifts and periods of transient ischemia during percutaneous translumina coronary angioplasty are less well tolerated by the hypertrophied ventricle in women. ${ }^{22}$

Women continue to have increased bleeding and vascular complications compared with men, but these rates have decreased with the use of smaller sheath sizes and early sheath removal, weightadjusted heparin dosing, and less aggressive anticoagulation regimens ${ }^{23}$. In bypass angioplasty revascularization investigation (BARI) trial women had a higher incidence of per procedural heart failure and pulmonary edema. ${ }^{24}$

Directional coronary atherectomy has been associated with lower procedural success and higher bleeding complications in women. ${ }^{25}$

\section{Elderly patients:}

Over 75 years age interventional procedures are associated with increased risk of complications ${ }^{26,27}$. Octogenarians undergoing percutaneous coronary intervention have a higher incidence of prior myocardial infraction, lower left ventricular ejection fraction, and more frequent HF. ${ }^{28,29}$ In the stent era, procedural success and restenosis rates are comparable to those for nonoctogenarians, although with higher incidences being reported for in-hospital and long-term mortality and for vas-cular and bleeding complications. ${ }^{30}$ There was a sig-nificant major bleeding rate in patients aged 75 years or older assigned to an invasive strategy. ${ }^{31}$ The incidence of stroke and major bleeding was also increased in the elderly at 1 year. Higher incidence of comorbidities and risk for bleeding complications should be taken into account when considering the need for percutaneous coronary intervention in elderly. ${ }^{32}$

\section{Diabetes Mellitus:}

An early invasive strategy after fibrinolysis was of little benefit in patients with diabetes. ${ }^{33}$ One year mortality and repeat revascularization were significantly higher in diabetics. ${ }^{34}$ Routine catheterization and percutaneous coronary intervention in patient with diabetes should be based on clinical need and ischemic risk stratification.

Stenting decreases the need for target vessel revasculariza-tion in diabetic patients compared with plain percutaneous translumina coronary angioplasty. ${ }^{35}$ The combination of stenting and use of abciximab in diabetics resulted in a significant reduction in 6-month rates of death and target vessel revascularization. ${ }^{36}$

Repeat revascularization was higher in the patients with diabetes. Drug eluting stent is superior over bare metal stent in terms of reducing late repeat revascularization. ${ }^{37}$

\section{Patients with Coronary Artery Bypass Surgery:}

Percutaneous coronary intervention of native vessels after prior coronary artery bypass graft have, in recent years, nearly equivalent interventional outcomes and complication rates compared with patients having similar interventions without prior surgery. For percutaneous coronary intervention of saphenous vein graft, studies indicate that the rate of successful angioplasty exceeds $90 \%$, the death rate is less than $1.2 \%$, and the rate of $\mathrm{Q}$-wave myocardial infraction is less than $2.5 \% .{ }^{38,39}$ The incidence of non $\mathrm{Q}$-wave myocardial infraction may be higher than that associated with native coronary arteries. ${ }^{40}$

In consideration of percutaneous coronary intervention for saphenous vein graft, the age of the saphenous vein graft and duration and severity of myocardial ischemia should be taken into consideration. The native vessels should be treated with percutaneous coronary intervention if feasible. 
In some circumstances, percutaneous coronary intervention of a protected left main coro-nary artery stenosis with a patent and functional left anterior descending or left circumflex coronary conduit can be considered. Percutaneous coronary intervention should be recognized as a palliative procedure with the potential to delay the ultimate application of repeat coronary artery bypass graft surgery.

Type of percutaneous coronary intervention: Primaqry percutaneous coronary intervention achieved modest reduction in overall mortality, need highly experienced team. life threatening complications of elective percutaneous coronary intervention are fortunately rare. Facilitated percutaneous coronary intervention has added cost and increased risk of bleeding, may helpful for high risk patients where percutaneous coronary intervention is not immediately available. Rescue percutaneous coronary intervention improved survival but failed to improved microcirculation. Use of antiplatelet therapy before and after procedure defend on type of stent, type of procedure and type of percutaneous coronary intervention. ${ }^{41}$

\section{Methods of percutaneous coronary intervention:}

Certain outcomes of percutaneous coronary intervention may be specifically related to the technology utilized for coronary recanalization. Periprocedural CK-MB elevation occurs more fre-quently after ablative technology such as rotational or directional atherectomy. ${ }^{42}$ Antecedent unstable angina appears to be a clinical predictor of slow flow and periprocedural infarction after ablative technologies, ${ }^{43}$ and direct platelet activation has been demonstrated to occur with both directional and rotational atherectomy. ${ }^{44}$

Coronary perforation may occur more commonly after the use of atheroablative devices, including rotational, directional, or extraction atherectomy, and excimer laser coronary angioplasty. However, the incidence of perforation has been reported variably to be $0.10 \%$ to $1.14 \%$ with balloon angio-plasty, $0.25 \%$ to $0.70 \%$ with directional coronary atherecto-my, $0.0 \%$ to $1.3 \%$ with rotational atherectomy, $1.3 \%$ to $2.1 \%$ with extraction atherectomy, and $1.9 \%$ to $2.0 \%$ after excimer laser coronary angioplasty. ${ }^{45,46}$ Coronary perforation complicates percutaneous coronary intervention more frequently in the elderly and in women. Although $20 \%$ of perforations may be secondary to the coronary guidewire, most are related to the specific tech-nology used.

Major adverse cardiac events (MACE) rates are reduced with the use of distal protection devices especially for interventions on saphenous vein grafts. ${ }^{47}$ Drug eluting bar metal stents can be used as an alternative to bare metal stents in those lesion subsets where randomized control trials have shown benefit from this technology. ${ }^{47}$

\section{Hemodynamic compromise:}

Hemodynamic compromise, defined as a decrease in systolic blood pressure to an absolute level less than $90 \mathrm{~mm} \mathrm{Hg}$ during balloon inflation, was often associated with left ventricular ejection fraction less than $35 \%$, greater than $50 \%$ of myocardium at risk, and percutaneous translumina coronary angioplasty per-formed on the last remaining vessel. ${ }^{45}$

Cardiopulmonary support should be reserved only for patients at the extreme end of the spectrum of hemodynamic compromise, such as those patients with extremely depressed left ventricular function and patients in cardiogenic shock. However, in patients with borderline hemodynamics, ongoing ischemia, or cardiogenic shock, insertion of an intraaortic balloon just before coronary instrumentation has been associated with improved out-comes. ${ }^{48,49}$

In patients having a higher-risk profile (such as those with left ventricular dysfunction, single patent vessel or unprotected left main, degenerated saphenous vein graft, or high thrombus burden in the obstructed vessel), consideration of alternative therapies, particularly coronary bypass surgery, formalized surgical standby, or periprocedural hemodynamic support should be addressed before proceeding with percutaneous coronary intervention. Several small retrospective studies have evaluated the use of elective balloon pump support before high-risk percutaneous coronary intervention shows suc-cessful reperfusion by percutaneous coronary intervention, with improved procedural or in-hospital morbidity and mortality. ${ }^{48,50,51}$

\section{Conclusion:}

Coronary angioplasty is a non-surgical technique for coronary arterial revascularization. With the experiences and advance technology now a days angioplasty has become more developed. Coronary 
angioplasty could be applied to broad group of coronary patients with higher rate of success and lower rate of complications. For the patients of percutaneous coronary intervention, variables influencing complications and outcome should be assessed to determine procedural risk, the risk of abrupt vessel closure, and potential for cardiovascular collapse. The clinical and angiographic variables associated with increased mortality need under consideration, include type $\mathrm{C}$ lesion, advanced age, female gender, diabetes, prior myocardial infraction, previous coronary artery bypass graft, multivessel disease, left main or equivalent coronary disease, a large area of myocardium at risk, pre-existing impairment of left ventricular or renal function and percutaneous coronary intervention in the setting of ST segment elevation myocardial infraction. For successful percutaneous coronary intervention need careful evaluation of patients and consider factors which may influences procedure adversely.

Conflict of Interest - None.

\section{References:}

1. Gruesntzig AR, Senning A, Siegenthaler WE. Nonoperative dilation of coronary artery stenosis: percutaneous transluminal coronary angioplasty. $N$ Engl J Med 1979; 301: 61-8.

2. Detre KM, Holubkov R, Kelsey S, et al. Percutaneous transluminal coronary angioplasty in 1985-1986 and 1977-1981: The National Heart, Lung and Blood Institute Registry. N Engl J Med 1983; 318 : 265-70.

3. O'Keefe JH, Jr. Rutherford BD, McConahay DR, et al. Multivessel coronary angioplasty from 1980 to 1989: procedural results and long-term outcome. J Am Coll Cardiol 1990; 16 : 1097-102.

4. Spencer BK III, Thomas A, William LB et al . ACCF/ AHA/SCAI 2007 Update of the clinical competence statement on cardiac interventional procedures. Circulation 2007; 116: 98-124 .

5. Ellis SG, Myler RK, King SB, III, et al. Causes and correlates of death after unsupported coronary angioplasty: implications for use of angioplasty and advanced support techniques in high-risk settings. Am J Cardiol 1991: 68: 1447-51.

6. Block P, Peterson E, Krone R, et al. Identification of variables needed to risk adjust outcome of coronary interventions: evi-dence-based guidelines for efficient data collection. J Am Coll Cardiol 1998; 32: 275-82.

7. Ellis SG Roubin GS, King SB, III, et al. Angiographic and clinical predictors of acute closure after native vessel coronary angioplasty. Circulation 1988: 77: 372-9.

8. Hartzler GO, Rutherford BD, McConahay DR, Johnson WL. Giorgi LV, "High-risk" percutaneous transluminal coronary angioplasty. Am J Cardiol 1988; 61: 33G-7G.

9. Tan KH, Sulke N, Taub N, Sowton E. Clinical and lesion morphologic determinants of coronary angioplasty success and complications: current experience. $J$ Am Coll Cardiol 1995; 25: 855-65.

10. Kimmel SE, Berlin JA, Strom BL, Laskey WK. Development and validation of simplified predictive index for major complications in contemporary percutaneous transluminal coronary angioplasty practice: the Registry Committee of the Society for Cardiac Angiography and Interventions. J Am Coll Cardiol 1995; 26: 931-8.

11. Rihal CS, Textor SC, Grill DE, et al. Incidence and prognostic importance of acute renal failure after percutaneous coronary intervention. Circulation 2002: 105: 2259-64.

12. Siotia A, Hancock P, Gunn J. Estimating the risk of percutaneous coronary intervention. Br J Cardrol 2006; 13: $39-45$.

13. Fuchs S, Stabile E, Kinnaird TD, et al. Stroke complicating percutaneous coronary interventions: incidence, predictors, and prognostic implications. Circulation 2002; 106: 86-91.

14. Krone RJ, Laskey WK, Johnson C. et al. A simplified lesion classification for predicting success and complications of coronary angioplasty. Registry Committee of the Society for Cardiac Angiography and Intervention. Am J Cardiol 2000; 85: 1179-84.

15. Chew DP, Bhatt DL, Robbins MA, et al. Incremental prognostic value of elevated baseline C-reactive protein among established markers of risk in percutaneous coronary intervention. Circulation 2001; 104: 992-7.

16. Mueller C, Neumann FJ, Perruchoud AP, Buettner HJ. Renal function and long term mortality after unstable angina/non-ST segment elevation myocardial infarction treated very early and predominantly with percutaneous coronary intervention. Heart 2004: 90: 902-7.

17. Eagle KA, Guyton RA, Davidoff R, et al ACC/AHA 2004 guideline update for coronary artery bypass graft surgery: summary article. A report of the American College of Cardiology/American Heart Association Task Force on Practice Guidelines (Committee to Update the 1999 Guidelines for Coronary Artery Bypass Graft Surgery). J Am Coll Cardiol 2004: 44: 1146-310.

18. Tan WA, Tamai H, Park SJ. et al. Long-term clinical outcomes after unprotected left main trunk percutaneous revascularization in 279 patients. Circulation 2001; 104: 1609-14.

19. Takagi T, Stankovic G, Finci L, et al. Results and longterm predictors of adverse clinical events after elective percutaneous inter-ventions on unprotected left main coronary artery. Circulation 2002: 106: 698-702.

20. Cowley MJ, Mullin SM, Kelsey SF, et al. Sex differences in early and long-term results of coronary angioplasty in the NHLBI PICA Registry. Circulation 1985; 71: 90-7.

21. Welty FK, Lewis SM, Kowalker W, Shubrooks SJ, Jr. Reasons for higher in-hospital mortality >24 hours after percutaneous translu-minal coronary angioplasty in women compared with men. Am J Cardiol 2001: 88: 473-7.

22. Greenberg MA, Mueller HS. Why the excess mortality in women after PTCA? Circulation 1993; 87: 1030-2.

23. Lansky AJ, Hochman JS, Ward PA, et al. Percutaneous coronary intervention and adjunctive pharmacotherapy 
in women: a state-ment for healthcare professionals from the American Heart Association. Circulation 2005; 1.11: $940-53$

24. Jacobs AK, Kelsey SF, Brooks MM, et al. Better outcome for women compared with men undergoing coronary revascularization: a report from the bypass angioplasty revascularization inves-tigation (BARI). Circulation 1998: 98: 1279-85.

25. Movsowitz HD, Emmi RP, Manginas A, et al. Directional coronary atherectomy in women compared with men. Clin Cardiol 1994: 17: 597-602.

26. Thompson RC, Holmes DR Jr, Gersh BJ, Mock MB, Bailey KR. Percutaneous transluminal coronary angioplasty in the elderly: early and long-term results. J Am Coll Cardiol 1991: 17: 1245-50.

27. Assali AR, Moustapha A, Sdringola S, et al. The dilemma of success: percutaneous coronary interventions in patients $>$ or $=75$ years of age-successful but associated with higher vascular com-plications and cardiac mortality. Catheter Cardiovasc Interv 2003: 59: 195-9.

28. Simpfendorfer C, Raymond R, Schraider J. et a!. Earlyand long-term results of pecutaneous transluminal coronary angioplasty in patients 70 years of age and older with angina pectoris. Am J Cardiol 1988; 62: 95961.

29. Klein LW, Block P, Brindis RG, et al. Percutaneous coronary interventions in octogenarians in the American College of Cardiology-National Cardiovascular Data Registry: development of a nomogram predictive of in-hospital mortality. J Am Coll Cardiol 2002: 40: 394-402.

30. Chauhan MS, Kuntz RE, Ho KL, et al. Coronary artery stenting in the aged. J Am Coll Cardiol 2001; 37: 856-62.

31. Bach RG, Cannon CP, Weintraub WS, et al. The effect of routine, early invasive management on outcome for elderly patients with non-ST-segment elevation acute coronary syndromes. Ann Intern Med 2004: 141: 186-95.

32. Batchelor WB, Anstrom KJ, Muhlbaier LH, et al. Contemporary outcome trends in the elderly undergoing percutaneous coronary interventions: results in 7,472 octogenarians. National Cardiovascular Network Collaboration. J Am Coll Cardiol 2000: 36: 723-30,

33. Aguine FV, Younis LT, Chaitman BR, et al. Early and 1-year clinical outcome of patients' evolving non-Qwave versus Q-wave myocardial infarction after thrombolysis: results from the TIMI II Study. Circulation 1995: 91: 2541-8.

34. Laskey WK, Selzer F, Vlachos HA, et al. Comparison of in-hospital and one-year outcomes in patients with and without diabetes mellitus undergoing percutaneous catheter intervention (from the National Heart, Lung, and Blood Institute Dynamic Registry). Am J Cardiol 2002: 90: 1062-7.

35. Gaxiola E, Vlietsra R, Browne KF, et al. Is the outcome of coro-nary stenting worse in elderly patients? $J$ Interven Cardiol 1998: 11: 37-40.

36. Marso SP, Lincoff AM, Ellis SG, et al. Optimizing the percutaneous interventional outcomes for patients with diabetes mellitus: results of the EP1STENT (Evaluation of platelet lib/Ilia inhibitor for stent-ing trial) diabetic substudy. Circulation 1999: 100: 2477-84.
37. Babapulle MN, Joseph L, Belisle P, Brophy JM, Eisenberg MJ. A hierarchical Bayesian meta-analysis of randomised clinical trials of drug-eluting stents. Lancet 2004: 364: 583-91.

38. Wong SC, Baim DS, Schalz RA, et al. Immediate results and late outcomes after stent implantation in saphenous vein graft lesions: the multicenter U.S. Palmaz-Schatz stent experience. The Palmaz-Schatz Stent Study Group. J Am Coll Cardiol 1995; 26: 704-12.

39. Gruberg L, Dangas O, Mehran R, et al. Percutaneous revascularization of the internal mammary artery graft; short- and long-term outcomes. J Am Coll Cardiol 2000; 35: 944-8.

40. Webb JG. Myler RK, Shaw RE, et al. Coronary angioplasty after coronary bypass surgery: initial results and late outcome in 422 patients. J Am Coll Cardiol 1990; 16: 812-20.

41. Smith SC, Feldman TE, Hirshfeld JW et al . ACC/AHA/ SCAI 2005 Guidelines Update for Percutaneous Coronary Intervention .Circulation 2006; 113: 156-175.

42. Teirstein PS, Warth DC, Haq N, et al. High speed rotational coronary atherectomy for patients with diffuse coronary artery disease. J Am Coll Cardiol 1991; 18: 1694-701.

43. Sharma SK, Dangas G, Mehran R. et al. Risk factors for the devel-opment of slow flow during rotational coronary atherectomy. Am J Cardiol 1997: 80: 219-22.

44. Dehmer GJ, Nichols TC, Bode AP, et al. Assessment of platelet activation by coronary sinus blood sampling during balloon angioplasty and directional coronary atherectomy. Am J Cardiol 1997; 80: 871-7.

45. Ellis SG, Ajluni S, Arnold AZ, et al. Increased coronary perforation in the new device era: incidence, classification, management, and outcome. Circulation 1994; 90: 2725-30.

46. Ajluni SC, Glazier S, Blankenship L, O'Neill WW, Safian RD. Perforations after percutaneous coronary interventions; clinical, angiographic, and therapeutic observations, Cathet Cardiovasc Diagn 1994: 32: 20612 .

47. Michael J. Lim, Morton J. Kern, St. Louis .The 2005 ACC/AHA/SCAI Percutaneous Coronary Intervention Guidelines: Summarizing changes and some of the major recommendations. Cath Lab Digest 2006; 14: 1 -10.

48. Kreidieh I, Da vies DW, Lim R, et al. High-risk coronary angioplasty with elective intra-aortic balloon pump support, Int J Cardiol 1992; 35: 147-52.

49. Anwar A, Mooney MR, Siertzer SH, et al. Intra-aortrc balloon counter pulsation support for elective coronary angioplasty in the setting of poor left ventricular function; a two center experience. J Invas Cardiol 1990: 2: $175-80$.

50 . Voudris V, Marco J, Morice MC, Fajadet J, Royer T. "Highrisk" percutaneous transluminal coronary angioplasty with preventive intra-aortic balloon counterpulsation. Cathet Cardiovasc Diagn 1990; 19: 160-4.

51. Khan JK, Rutherford BD, McConahay DR, Johnson WL, Giorgi LV, Hartzler GO. Supported "high risk." coronary angioplasty using intraaoitic balloon pump counterpulsation. J Am Coll Cardiol 1990; 15: 1151-5. 